\title{
Psychological factors motivating the choice of university entrants
}

\author{
Tetiana Derkach**, Alla Kolodyazhna, and Yana Shuhailo \\ ${ }^{1}$ Kyiv National University of Technologies and Design, 2 Nemyrovych-Danchenko Str., Kyiv, 01011, Ukraine
}

\begin{abstract}
The article focuses on the study of factors influencing the choice of a university by entrants. Firstyear students' behaviour is mainly affected by external factors or factors not related to professional educational trajectory choice. An individual choice considers the limitations imposed by the size of family capital, abilities and other characteristics of the applicant, institutional factors (development of infrastructure, etc.). These restrictions affect the choice of future profession and a particular university, which largely determines the education quality. The most popular sources to receive information about universities are the official websites. The analysis of entrants' answers can become the basis for universities' PR and advertising programs. They will also be useful for optimising the content of the website. The university presentation's quality is one of the most critical factors in the independent search for a university without pre-established benefits. Advertising campaigns should be dominated by motives that promote a particular choice. They are the university's overall image, teachers' professionalism, and a clear definition of the actual possibilities for further work in the speciality.
\end{abstract}

\section{Introduction}

A common problem in many universities is the reduction in the number of applicants wishing to receive relevant education. As a result, the quantity of qualified personnel is declining. It is a problem not only for Ukraine. Many European countries are experiencing similar difficulties, where the number of students continues to decline [1-3]. Interest in technical and natural disciplines is especially noticeably falling [4-6]. Conversely, the population of the regions of Asia and North Africa is multiplying. The number of young people seeking to obtain higher education is growing [7].

The problem of declining student numbers in Ukraine has both objective and subjective reasons. Of the two reasons, the former is due to the demographic situation. The latter is more concerned with engineering or technological professions caused by the continuing decline in the Ukrainian industry. The problem is associated with a change in the number of manufacturing companies, low wages, and the lack of competitive Ukrainian products compared to cheap imports. All this affects future applicants' ideas about the prestige and prospects of engineering or technological professions [8-10].

Nevertheless, the popularity of specialities does not fully meet the requirements of the labour market. On the one hand, many engineering majors, as well as majors in natural sciences, are currently undervalued. However, their role will be vital for the development of industry and economy shortly. On the other hand, many social specialities or legal studies are overestimated. As a result,

*e-mail: derkach.tm@knutd.edu.ua graduates of such specialities cannot find their place in the labour market [11].

The Ministry of Education and Science of Ukraine is making efforts to eliminate this deformation. Nevertheless, we cannot say that the results are very impressive because this is a long process. It takes several years for the fruits of efforts to appear. It is also possible that the means used are not the most optimal. The problem at the level of the ministry smoothly flows into a problem at the university level. The question arises whether universities maximally use the right tools and opportunities or not.

Much attention is paid to individualisation issues in search of ways to interact with future students [12]. It takes a lot of effort and time. The following directions are important in the individualisation of higher education.

The first item concerns the identification of factors influencing the effectiveness of students' study of various disciplines. Scientists mainly study individualtypological characteristics of individuals (types of intelligence, psychological and physiological characteristics, etc.). The quantitative and qualitative composition of students' formed learning styles is most often mentioned as an integral and the most influential factor [13-15]. Teachers and students pay attention to expecting and preventing so-called "style conflicts" in modern publications.

Another area includes studying changes in students' cognitive load as a function of their characteristics, the type of material they master, the variety of resources used by teachers, etc. The specialists' efforts aim to identify the factors that cause a significant increase in cognitive load and the development of tools for managing it.

The formation of market relations creates novel approaches and additional problems in higher education. The 
rapid growth and development of the educational services' market initiate new educational institutions of different types. The increase in the number of educational institutions that train specialists in various fields and profiles makes the problem of choosing a university among many alternatives even more apparent.

The choice of university is a strategic point of further professional and personal development [16]. Responsible choice characterises a person as a subject of his/her own life, constructing his/her way of life. This problem becomes especially important in adolescence. A person makes a significant step towards adulthood, facing the need to make several vital choices, particularly university choice. The wrong choice of university and speciality becomes a crucial personal problem, which leads to dissatisfaction with professional activities, the comprehension that a large amount of time and money was wasted [17].

The problem of motivation in choosing a university is essentially a problem of efficiency and quality of education, which is obtained. It also acts as a problem of socio-psychological adaptation of students to the learning process conditions [18]. The motive of entrant choice is a question about the university's socio-economic success and the possibilities of implementing the experience gained by its graduates. Ultimately, the motivation for continuing professional self-education should result from higher education.

Today, higher education is becoming widespread, so most students are focused on obtaining it. However, the motives are formed in different degrees and by various factors [19-21]. University entrants rarely have a clear understanding or experience in the future profession, and this problem is unlikely to be solved. However, the university, which has traditions, history, and rich experience, can reveal professional activity specifics during the admission campaign. It requires constant monitoring of the values and targets of entrants.

In this regard, well-established communication with potential students is essential for university management $[22,23]$. It is necessary to understand how entrants choose universities, what criteria are considered, which specialities are popular, and who decides on a university and speciality choice. In other words, each university, presenting a relatively extensive list of educational services, tries to attract the largest number of consumers. In turn, applicants and their parents, choosing a university, decide how well they provide these services.

The most critical element of competition between universities for the most talented and interested entrants is an adequate information and communication system. It should allow an entrant to quickly receive reliable, complete and useful information about the university from a perceived source [24, 25]. Deciding based on the received data, the entrant evaluates its usefulness and availability. An open, transparent communication channel is a good competitive advantage for the university in the education market. By the time of application, prospective students usually already know what speciality they plan to enter and what awaits them in the learning process and after graduation.
The article aims to study the psychological factors that shape applicants' demand and determine their behaviour during admission to the university. The work is focused on identifying possible ways to increase motivation and attract future students to obtain engineering and technological specialities.

\section{Experimental}

The experiment was based on a survey conducted among first-year students studying at six faculties of the Kyiv National University of Technologies and Design (KNUTD). The survey was conducted by questionnaire in early 2019. A total of 561 people were admitted to study in 2018. Two hundred ninety-five students (114 boys and 181 girls) took part in the survey ex proprio motu. Therefore, the survey covered almost $53 \%$ of the total number of first-year students. Table 1 illustrates the distributions of survey respondents and first-year students by faculties together with faculties' names, including abbreviations.

Table 1. Number of first-year students admitted by faculties and participated in the survey

\begin{tabular}{|c|c|c|c|c|}
\hline & \multicolumn{2}{|c|}{ surveyd } & \multicolumn{2}{|c|}{ admitted } \\
\hline Faculties & peo & & peop & \\
\hline Design (D) & 81 & 27 & 165 & 49 \\
\hline Economics \& Business (EB) & 71 & 24 & 120 & 59 \\
\hline Fashion Industry (FI) & 17 & 6 & 26 & 65 \\
\hline $\begin{array}{l}\text { Mechatronics \& Computer } \\
\text { Technologies (MCT) }\end{array}$ & 49 & 17 & 55 & 89 \\
\hline $\begin{array}{l}\text { Entrepreneurship \& Law } \\
\text { (EL) }\end{array}$ & 39 & 13 & 129 & 30 \\
\hline $\begin{array}{l}\text { Chemical \& Biopharmaceu- } \\
\text { tical Technologies (CBT) }\end{array}$ & 38 & 13 & 66 & 58 \\
\hline Total & 29 & & 561 & 53 \\
\hline
\end{tabular}

The questionnaire contained 11 questions and general information on age, sex, affiliation to the faculty and speciality. For each question, respondents were given several answers. All items can be grouped according to their focus. The problems of the first group (five questions) were aimed at describing the collective profile of the respondents:

1. Where did you finish secondary school?

2. Profile of the class in which you studied.

3. The average score of the certificate.

4. What subjects did you like at school?

5. What disciplines did you test in independent external testing (IET)?

The second group comprised four questions aimed at determining the key factors that served as the motive for the choice of KNUTD. The items in this group were as follows:

1. You chose KNUTD because... 


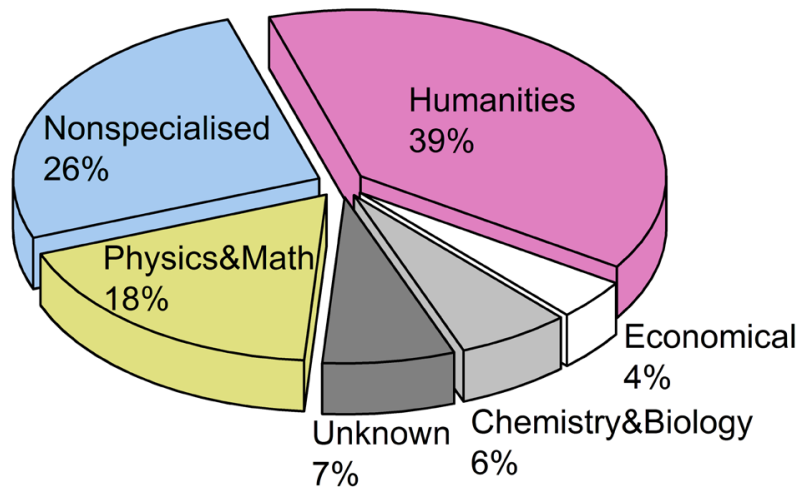

Figure 1. Distribution of entrants by school specialisation

2. Indicate what attracted you to your chosen speciality.

3. Identify among the listed factors that influenced your choice of a higher education institution.

4. Have you registered applications for admission to a few various universities?

Two other issues concerned the information channels involved in the process of university selection. These questions are worded as follows:

1. Where did you get information about KNUTD and specialities that you liked?

2. Your choice of speciality was due to (specify).

The answers obtained during the survey were processed to understand entrants' motivation when choosing a university and specialities and identify the most effective channels for conveying the information to entrants.

The results obtained were presented in the form of ratings. This type of presentation usually does not require statistical processing of responses. Ratings are used to illustrate observed preferences qualitatively. They do not reveal the presence or absence of statistically significant differences between individual groups of responses.

\section{Results}

\subsection{Profiles of respondents}

Two hundred ninety-five first-year students took part in the survey. The largest number of entrants (53.7\%) came from the cities of Ukraine (regional and district centres). Another $33.9 \%$ came from rural areas. The share of entrants from Kyiv was relatively small $-12.4 \%$.

Entrants studied in secondary schools with different specialisations. The distribution of the number of entrants by school specialisations is shown in figure 1 .

Graduates of humanities and non-specialised schools account for almost two-thirds of the total number of students. Together with graduates of physics and mathematics schools, these three school types' share reaches $83 \%$.

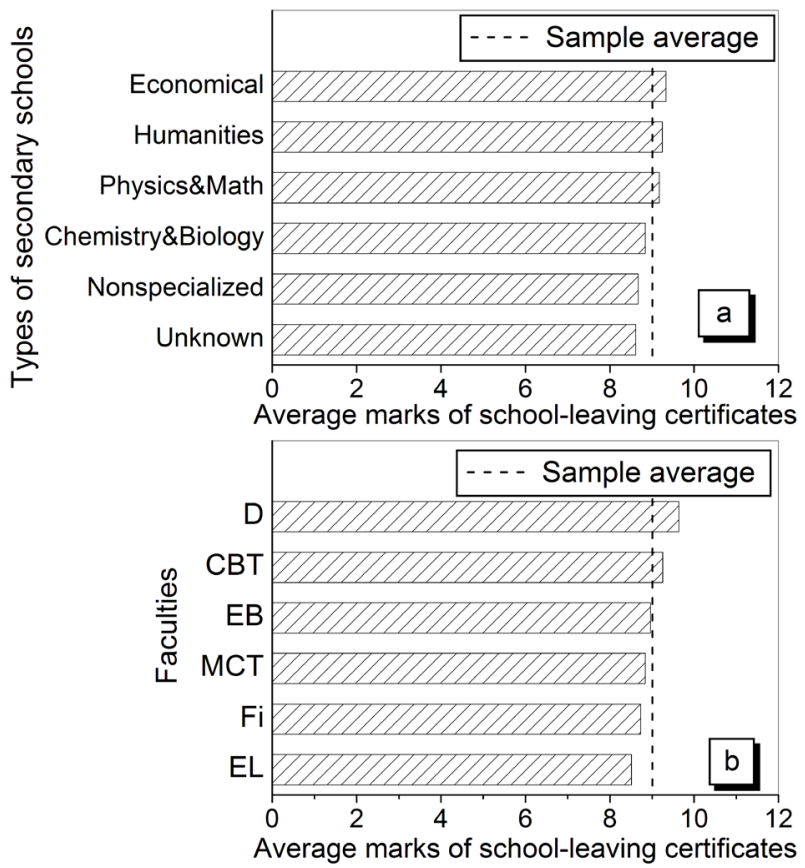

Figure 2. Average school certificate scores by school specialisation (a) and by faculties (b)

The average certificate scores are shown in figure $2 \mathrm{a}$ for entrants after schools of different specialisations. They are shown in figure $2 \mathrm{~b}$ for first-year students at different faculties.

As seen from figure $2 \mathrm{a}$, three types of schools (economic, humanitarian and physical-mathematical profiles) provide high (above average) scores in certificates. Conversely, graduates of the other three types of schools are characterised by relatively low scores of certificates.

Therefore, the structure of entrants by origin affects the average certificate scores at different faculties (figure 2b). For example, graduates of humanities and physics and mathematics schools make up over $71 \%$ of the total number of first-year students in the Faculty of Design. The share of graduates from non-specialised and non-established schools is only $21 \%$. Therefore, the average score of certificates for newcomers at this faculty is the highest among other faculties. Conversely, among FEL entrants, the shares of the schools mentioned above with high and low average grades are $54 \%$ and $40 \%$, respectively.

Specialities at the university differ in the level of popularity. More and less popular specialities can coexist at the same faculties. The number of students admitted to the speciality is an obvious measure of its popularity. It is conventionally accepted that prevalent specialities recruit over 30 students. Specialities with medium popularity have from 20 to 29 students, low - less than 20 students. Twenty-nine specialities at the university can be classified as unpopular, three exhibits an average level of popularity, and seven are very popular. 


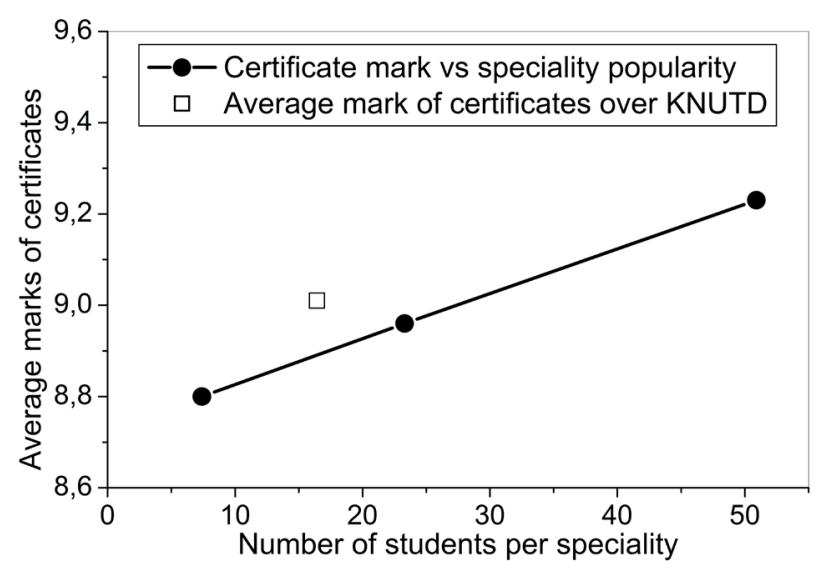

Figure 3. Correlation between the popularity of the speciality, expressed in the number of enrolled students, and the average score of their school certificates

Figure 3 illustrates the existing correlation between popularity and the average score of school certificates among students enrolled in these specialities.

There is a natural change in the average score from higher to lower with decreasing popularity of specialities. The obvious conclusion is that entrants with better certificates have a wider choice of specialities, including the opportunity to choose more popular ones.

An essential characteristic of the entrants was the existing preferences over the subjects studied at school. These preferences characterised the propensity of students to learn in a particular field. They also served as one of the factors in choosing a speciality for admission.

Respondents expressed their preferences for specific disciplines twice, indicating preferences for school subjects (figure 4a) and listing the subjects tested by IET (figure $4 \mathrm{~b}$ ). In both cases, the number of items was not limited. The answers to figure 4 are given in relative units normalised to either the total number of mentioned subjects (figure $4 a$ ) or the total number of students (figure $4 b$ ).

The leaders among school preferences were the Ukrainian language, mathematics, history and foreign language. At least $15 \%$ of the total number of students expressed a favourable attitude to these subjects (figure 4a). A much smaller part preferred biology and geography, and chemistry and physics are among outsiders.

The picture looks similar among the external evaluation subjects: the three leaders of popularity and two outsiders have not changed. The result in Figure $4 \mathrm{~b}$ indicates the existence of an objective factor that influences the choice of speciality. The lack of external evaluation makes it impossible for applicants to apply for budget proposals for specialities. For example, certificates in chemistry or physics are required.

Additional information on applicants' behaviour is provided by answering the simultaneous registration questions for admission to different universities. Only $14 \%$ of the total number of respondents limited their plans to join KNUTD only. The vast majority of entrants tried to enter various educational institutions at the same time.

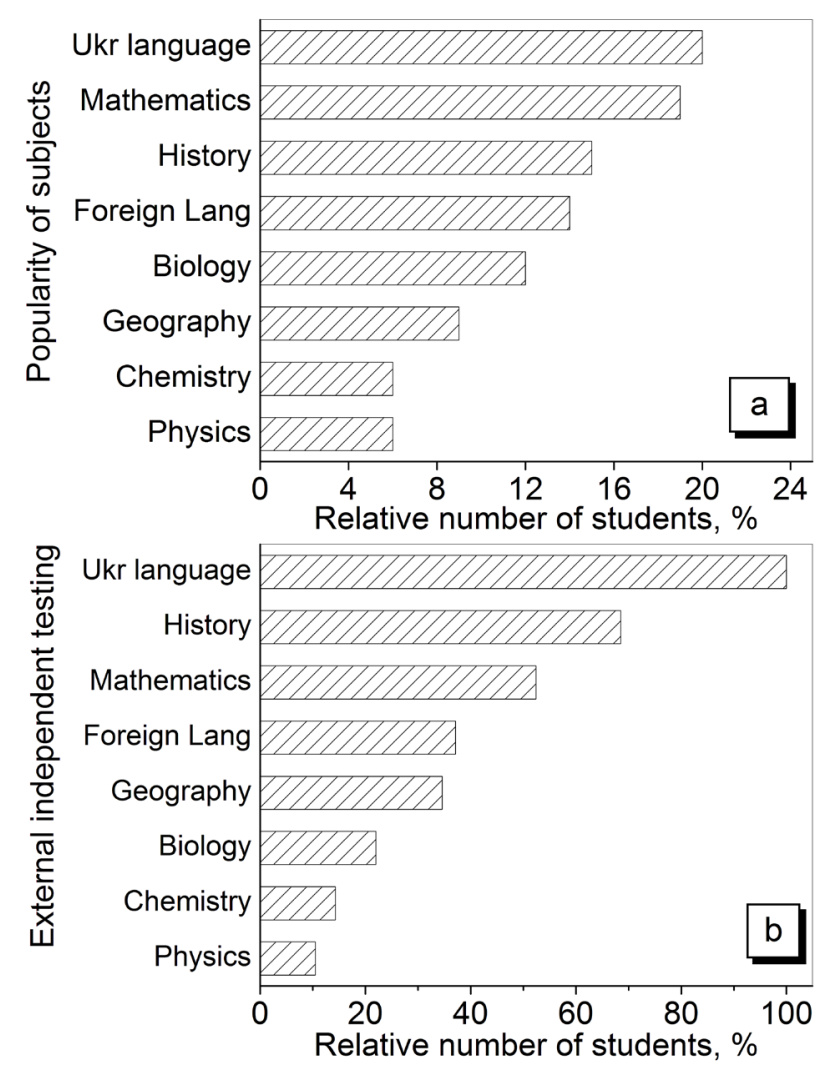

Figure 4. Subjects that were named as popular at school (a) and were selected for the IET (b)

\subsection{Motivation}

The motivation of students in choosing a speciality has been studied in great detail. Relevant questions and possible answers to them are created for three levels of research of influencing factors. At the first level, the influencing factors concern the chosen university speciality or profession. At the second level, they cover the existing advantages of the selected university compared to other educational institutions. Variants of the influence of various personal factors are investigated at the third level. The results are shown in figure $5 \mathrm{a}-\mathrm{c}$.

Among the factors related to the chosen profession (figure 5a), the existing high prospects for professional growth and the possibility of further work in the speciality dominate among students' preferences. Together, these two factors are present in the answers of $75 \%$ of respondents. The influence of such factors is likely related to industrial development and the availability of jobs. The contribution of other factors in the choice of a profession does not exceed $17 \%$.

Another type of factors, which is analysed in figure $5 \mathrm{~b}$, can be conditionally attributed to the reasons that forced students to enter KNUTD and not another university. These factors are closely related to the positions and advantages of KNUTD. They are a big city location that provides additional opportunities to work concurrently with studies and the university's position in various rankings. Such benefits are mentioned in at least $40 \%$ of 


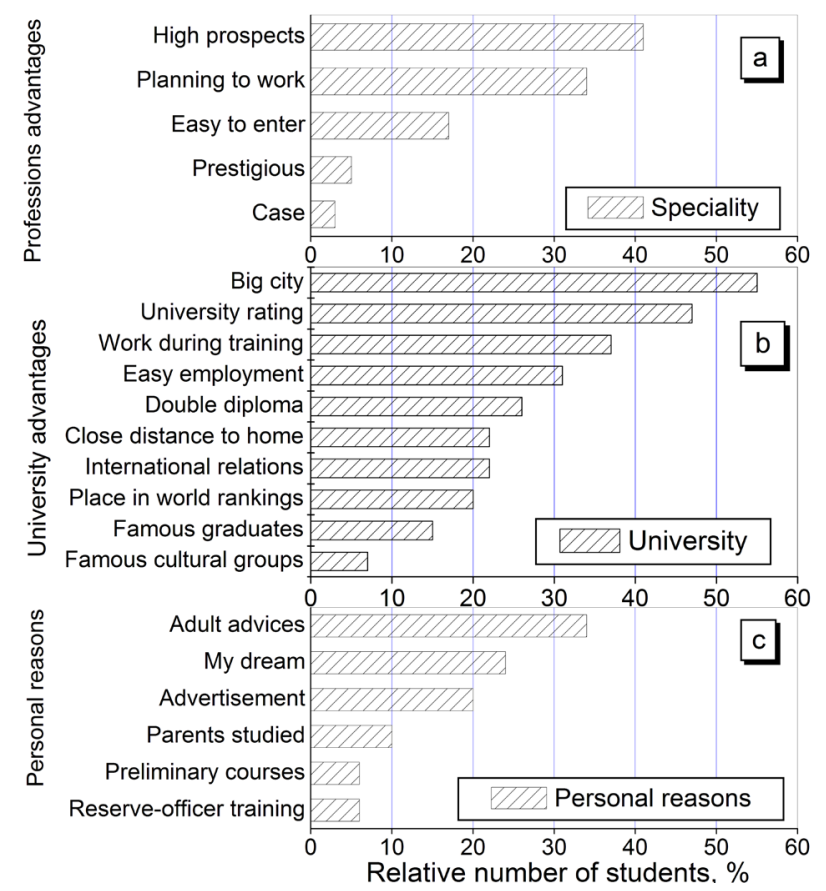

Figure 5. Main attractions in the speciality (a) and the reasons of different origin for admission to KNUTD (b, c)

the students' responses. About a third of the respondents consider the expected ease of employment and the opportunity to obtain a double degree as a significant advantage.

Another type of factors analysed in figure $5 \mathrm{c}$ can be conditionally attributed to the category of external and internal motivations of an individual. About $78 \%$ of respondents note that the decision to join was facilitated by adult advice, advertising materials or their dream of studying at KNUTD. Other factors, as motivations, were not very significant.

\subsection{Information channels}

The question of how to obtain information on KNUTD concerned either the popularity of different information channels (figure 6a) or the role of information dissemination through people (figure $6 \mathrm{~b}$ ).

The results show that most students receive information about KNUTD on the university website. Communication with relatives and friends (especially with those already studying at KNUTD) is also influential.

The low percentage of students who received information during the open days is noteworthy. There is almost no influence of print advertising and the university's Facebook page. The impact of interaction with school and KNUTD teachers is mentioned by only $1-2 \%$ of the surveyed freshmen (figure 6a).

Communicating with people is also an important way of obtaining information. As seen in figure $6 \mathrm{~b}$, entrants consider their own beliefs the primary reason for choosing (57\% of all answers). This fact contradicts the results of the entrants' answers to another question. It is clear from figure $5 \mathrm{c}$ that they make decisions based on adults' and
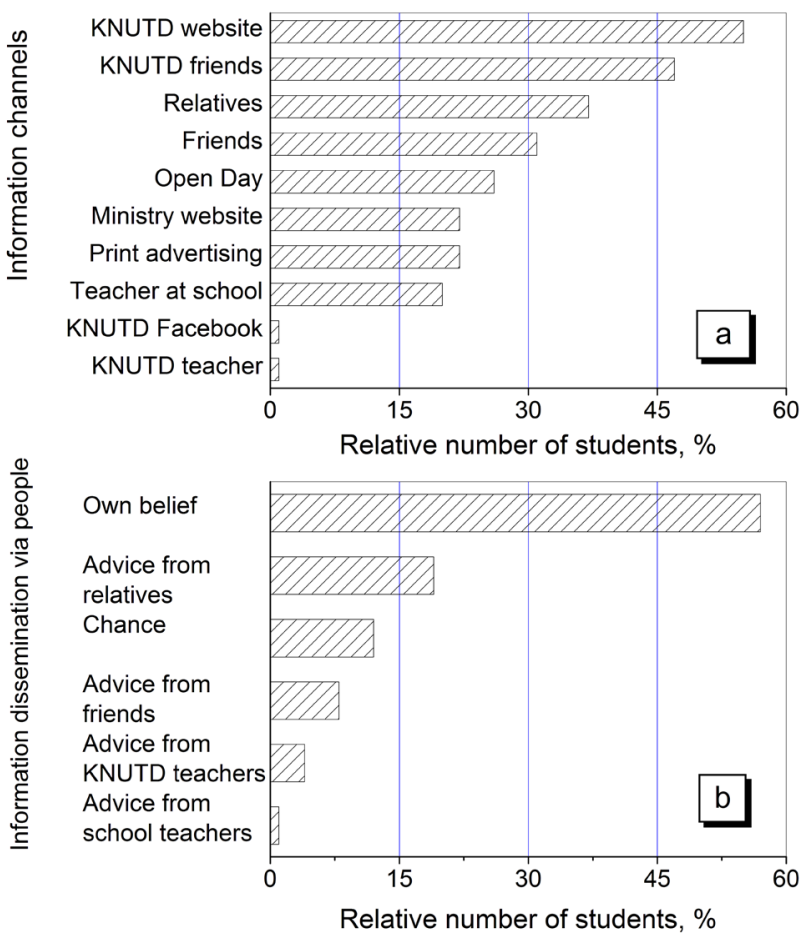

Figure 6. Channels for the transmission of information about KNUTD (a) and ways for the dissemination of information through people (b)

parents' advice in $34 \%$ of cases. An explanation may be the peculiarity of the age of entrants' psychology (17-18 years). They attach great importance to their independence and do not reflect on how they decided. It is also clear that there is no influence through school and KNUTD teachers (about $5 \%$ of answers in sum).

\section{Discussion}

\subsection{Psychology of motivation for university entrants}

In analysing the motivational sphere, scientists distinguish between internal and external motivation types [26, 27]. The system of external motivation is associated with instrumental activities and an external control system. Increasing the complexity of the situation leads to an increase in tension, which the body seeks to relieve. When the goal of the instrumental activity is achieved, a state of pleasure and relaxation ensues. Internal motivation is a self-activity and internal control system, search for tension and difficulties, accompanied by interest and inspiration.

By the above approach, the motives for choosing a university are divided into external (advice from friends, for example) and internal (e.g., interest in a particular activity). The obtained results indicate a more significant influence of external factors.

Each entrant has goals and desires that shape his behaviour and ways to achieve professional plans. It is the reason for choosing a speciality for $29 \%$ of the respondents. However, the choice of the $(49 \%)$ was influenced 
by the advice of friends and reputable adults. It follows from the survey results and is entirely consistent with the literature data [28].

The position of senior family members deserves special attention $[29,30]$. The behaviour of young people and their parents can be considered primarily adaptive from a psychological viewpoint $[31,32]$ Thus, the choice of the speciality of future students is dependent and indirect. Parents become the primary agents of choice in high uncertainty conditions, thus sharing the risk of possible unsuccessful choice. By adapting to the conditions of competition for places in universities, parents use social, informational, and economic resources and contribute to the rational use of children's intellectual resources.

Also, the relationship between parents and children in this situation is entirely consistent with the provisions of the theory of rational choice [33]. The transfer of control is most likely when the outcome of the action is uncertain rather than pre-determined. If a person believes that the transfer of control over his actions to another person, in this case, the parents, will lead to a better result, then such a transfer seems rational.

However, the survey showed that both personal interest and the opinion of parents are essential factors in choosing a speciality and university. Moreover, personal interest is more often shown when choosing a speciality (82\%), and the view of parents contributes to choosing both a speciality $(26 \%)$ and a university $(12 \%)$.

However, personal desires and needs are not determinative factors of future students' choice, although they play a role. There is a contradiction between the indication of parents' significant role and the high percentage of respondents who consider their choice of a speciality an independent decision. We believe that the phenomenon of infantilism is the basis of the revealed contradiction $[34,35]$.

The psychology of the development of entrants' choice can explain such a contradiction. The sincerity of the respondents' answers about independent decision-making at this age raises reasonable doubts, even in an anonymous questionnaire. The reason is as follows. A competent and timely statement or opinion about professional activity in any field is often heard from an authoritative person. Such an idea can be easily, unconsciously and automatically transformed into a young person's own belief. As a result, respondents claim that their choices are based on their own beliefs.

Career prospects in terms of future upward mobility and the realisation of young people's ambitions and needs were essential in choosing a speciality. Opportunities to get a prestigious position with the prospect of career growth were noted by almost $61 \%$ of the respondents. $52 \%$ of the respondents chose their speciality, not by chance, but because they plan to work in this speciality.

These indicators are related to the prestige of the university. In recent years, rankings have become an essential attribute of the global market for educational services. Although none of them can offer an objective picture, this tool today forms a social reality. The survey results are evident; namely, $47 \%$ of entrants paid attention to the place of KNUTD in the ranking of higher education institutions in Ukraine and $20 \%$ to the position in the world rankings.

One of the factors that influenced the choice of KNUTD was the position "Presence of well-known graduates, whose name became a product brand, etc." (15\%). This factor is based on parents' and friends' stories about successful careers that may have taken place. Of course, it does not consider the real ratio of successful and unsuccessful careers after graduation. Nevertheless, it significantly affects the consciousness of students and entrants.

Factors such as "accidentally joined" (5\%) and "not difficult to join" (6\%) were not widespread among the respondents.

The study revealed the influence of institutional factors on the decision to choose a university. A reasonably necessary component of choice ( $28 \%$ ) is the availability of a developed educational infrastructure (dormitories, libraries, classrooms, cafeterias, etc.). The presence of well-known dance, vocal and other groups as a factor of influence has a low rate $(7 \%)$. It is explained by the fact that modern youth has a rather pragmatic mind-set. Mostly, students try to work in their spare time to provide decent living conditions. The university's location in the downtown area significantly influences entrants' choice $(55 \%)$. Thus, this external factor must also be taken into account. Applicants want to live in a liveable city with a high standard of living, higher career prospects, etc.

Simultaneously, some students showed conformist sentiments, choosing "proximity to home" in the university's location (22\%). Of course, this factor can be attributed to random. However, it would be unwise not to use it to attract students to the university. The criterion "parents or relatives studied here" is represented by insignificant values (12\%). Such a result shows that family tradition currently does not significantly affect the choice of profession. Young people do not seek to follow the family dynasties.

The strategy of development of the educational field of KNUTD is aimed at creating new educational formats, namely: the possibility of obtaining a double diploma (26\%), the opportunity to combine work and study (37\%), international relations, working mobility programs (22\%). All these are factors helped the students of KNUTD to decide on admission.

As a rule, the profession choice is determined by a combination of factors rather than a single factor [36]. Professional self-determination depends on abilities, family characteristics (status, education, material level), professions' social prestige, the media's role, and more. Some of these factors are the leading ones. The choice of educational institution was influenced by internal (interest in the profession, abilities, etc.) and external factors (location of the university, parents' opinion, etc.) As seen from the respondents' answers, external agents dominate.

\subsection{Effective information channels}

The essential tool to attract and influence competition between universities for the most talented and interested applicants is an adequate information and communication 
system. Such a system quickly provides an applicant with reliable, complete and useful information about the university. An open, transparent communication channel is a significant competitive advantage of the university in the education market.

Analysis of the study results shows that the most popular information source was the official website of KNUTD. It was preferred by $65 \%$ of the respondents. Only $24 \%$ of the respondents made their choice thanks to the university's advertising campaign. A small group of respondents (8\%) completed the final decision while studying at the university's preparatory courses.

As one can see, KNUTD entrants focus on prompt receipt of informative answers from the Internet, i.e. the maximum useful information on the website. It is also due to the group membership of entrants. A significant part of future students are residents of small towns and villages, most of which are far from Kyiv.

The all-university resource of KNUTD contains a separate section, "For entrants", which provides answers to admission's central questions. Information about the university's rating and its connections with employers is vital. Going to the pages of departments, users see information about the staff and history, which is useful, on the one hand. On the other hand, it does not form a good idea of the future speciality as follows from the survey results.

Therefore, it is desirable to change the design of the pages of departments. It seems logical to implement a well-known model of consumer behaviour AIDA (Attention, Interest, Desire, Action) [37]. The website needs to use tools that not only attract attention but also retain the visitor. The more time he spends on the website, the greater the likelihood of interest in specific proposals of a university. Various forms of interaction act as tools of interest creation. They are, for example, online quizzes and competitions, online testing of senior pupils, establishing the level of knowledge, etc.

Further, the website should help to transform the interest of the applicant into a desire. As a desire, in this case, we mean the desire to obtain more detailed information about the university and its structures. As an action, we understand the desired result, such as submitting applications and original documents and other applicant steps, leading to this result. They include registering for offline events, attending them, joining a university group on a social network, calling the admissions office, and more. In this regard, the main tools of the website, motivating to action, are all forms of feedback and contact with the applicant: buttons for interactive interaction "ask a question to the staff of the selection committee/order a call", online application services, social network buttons, etc.

One of the motives for youth professional formation is career guidance work, which is defined as a system of social and pedagogical influence on young people to prepare them for a conscious choice of profession. However, the results of the survey suggest that KNUTD (2\%) and school teachers (3\%), as well as the open days at the university $(13 \%)$, do not practically influence the choice of future profession.
Career guidance is essential not only for the development of a young person's personality but also for society [28]. The result of professional self-determination is the performance by a young specialist of socially essential activities aimed at the production of a socially valuable product. However, today the career guidance work of the university is objectively selective. It can be defined as electoral career guidance to select the best entrants (high scores of IET, winners of school competitions, etc.). Universities are forced to build a system of career guidance that implements a selective approach at best. In the most extreme case, it is a recruiting strategy when all applicants are enrolled in the first year.

The analysis of channels and tools to influence entrants' motivation allows us to argue about the variety of existing tools for attracting applicants. The effectiveness of the information and communication system depends on the total number of tools used and their ability to influence entrants at all consumer behaviour stages.

\section{Conclusions}

1. Freshmen are mainly focused on external factors of university choice or factors not related to the will of professional educational trajectory. Of course, this trend leads to inevitable consequences at different levels. At the personal level, it leads to "professional frustration", depressed mood, intra-personal conflicts, lost time and money. It turns into the loss of "their" entrants and decreased prestige at the university level. At the level of society, it causes irrational use of money by the government, rising youth unemployment, lack of qualified personnel. All this suggests the need for better career guidance work that can provide a more informed profession choice.

2. A specific individual choice is made quite rationally. It considers the limitations imposed by the amount of family capital, abilities and other characteristics of the applicant, institutional factors (development of educational infrastructure in the region, etc.). These restrictions affect the choice of the future profession and a particular university, which largely determine the quality of education.

3. The official website is the most popular source of information for the entrant. It is necessary to pay attention to its content with important and interesting news to ensure entrants' maximum awareness. It is possible to increase the number of entrants by optimising career guidance information. One needs to consider the most influential factors, highlight important information for entrants, establish information communication channels, and attract optimal technologies for interaction with applicants.

4. Applied research to study the motives is useful only if they are information for reflection and simultaneously a university's PR and advertising program. Such a program should focus on the target groups of educational services consumers. The quality of 
a university presentation is one of the most critical factors that act in the independent search for an educational institution without pre-established advantages. If the entrant's first impression has been generally positive, then he is more willing to cooperate.

5. The university's PR program is a necessary element, without which the implementation of educational policy is impossible today. Each university has a specific target audience for which it works: senior students and entrants, their parents. Therefore, to increase the popularity of the university, efforts are needed to promote its brand. Moreover, the advertising campaigns should be dominated by motives that motivate a particular choice: the overall image of the university, the professionalism of teachers, evident areas for further work in the speciality. One needs to intensify work with potential employers. The university's PR concerning future students promotes the educational institution, posting announcements about the university's life and employment of graduates after graduation.

6. A contradiction is observed between the positioning of students ("we make decisions independently") and the factors that influence their decisions (parents and adults) in reality. This contradiction is explained by theories of manifestations of infantilism, rational choice and adaptive human behaviour in conditions of high uncertainty. Information interaction with entrants and their parents must be built, taking into account these theories' provisions.

The authors would like to thank Dr. R. Kyrychenko for her assistance in the organisation of the survey.

\section{References}

[1] R. Brooks, Compare: A Journal of Comparative and International Education 48, 500 (2018)

[2] Eurostat: Statistic Explained, Tertiary education statistics (2020), https://ec.europa.eu/ eurostat/statistics-explained/index. php/Tertiary\_education\_statistics

[3] OECD, Number of students (2018), https://data.oecd.org/eduresource/ number-of-students.htm

[4] S. Avargil, Z. Kohen, Y.J. Dori, Chem. Educ. Res. Pract. 21, 668 (2020)

[5] H. Mishkin, N. Wangrowicz, D. Dori, Y.J. Dori, Procedia - Social and Behavioral Sciences 228, 222 (2016), 2nd International Conference on Higher Education Advances,HEAd'16, 21-23 June 2016, València, Spain

[6] M. Suhail, A.U. Rahman, eds., West Asia and North Africa: Changing Paradigms (New Green Print Solutions, 2019)

[7] O.B. Morhulets, O.V. Nyshenko, Management 30 (2019)
[8] K. Omelchenko, O. Solomka, Scientific Works of NUFT 24, 73-79 (2018)

[9] S.O. Ischuk, Y.V. Kudria, Economics and Law 44, 31-39 (2016)

[10] D. Ardura, Á. Zamora, A. Pèrez-Bitriàn, Chem. Educ. Res. Pract. 22, 43 (2021)

[11] L. Angelis, N. Bassiliades, Y. Manolopoulos, COLLNET Journal of Scientometrics and Information Management 13, 11 (2019)

[12] I.V. Vainshtein, V.A. Shershneva, R.V. Esin, M.V. Noskov, Journal of Siberian Federal University. Humanities \& Social Sciences 12, 1753-1770 (2019)

[13] T. Derkach, T. Starova, Science and education pp. 51-56 (2017)

[14] T.M. Derkach, Information Technologies and Learning Tools 66, 139 (2018)

[15] T. Derkach, Advanced Education pp. 55-61 (2018)

[16] V. O’Reilly, M. McMahon, P. Parker, Australian Journal of Career Development 29, 79 (2020)

[17] V.L. Pogribna, I.V. Pidkurkova, The Bulletin of Yaroslav Mudryi National Law University. Series:Philosophy, philosophies of law, political science, sociology 4, 106-117 (2017)

[18] A. Oxenswärdh, Millennium 2, 33-43 (2017)

[19] X. Wang, American Educational Research Journal 50, 1081 (2013)

[20] B.E. Woolnough, International Journal of Science Education 16, 659 (1994)

[21] J.M. Safranková, M. Sikyr, International Journal of Teaching and Education IV, 48 (2016)

[22] A. Izquierdo-Yusta, A.I. Jiménez-Zarco, I. GonzálezGonzález, C.M. Gómez-Cantó, Journal of Management and Business Education 3, 108-128 (2016)

[23] A. Belov, G. Chernova, V. Khalin, N. Kuznetsova, L. Belinskaja, Management Theory and Studies for Rural Business and Infrastructure Development 42, 193-205 (2020)

[24] V.G. Shcherbak, O.O. Shevchenko, Management 31, 81-86 (2020)

[25] P. Acosta-Vargas, C. Ramos-Galarza, L. SalvadorUllauri, G.E. Chanchí, J. Jadán-Guerrero, Improve Accessibility and Visibility of Selected University Websites, in Advances in Human Factors and Systems Interaction, edited by I.L. Nunes (Springer International Publishing, Cham, 2020), pp. 229-235, ISBN 978-3-030-51369-6

[26] J. Smith, Motivation, Internal and External (Springer International Publishing, Cham, 2017), pp. 67-77, ISBN 978-3-319-49460-9

[27] K. Weber, Communication Research Reports 20, 376 (2003)

[28] E.A. Klimov, Psykholohyia professyonalnoho samoopredelenyia (Psychology of professional self-determination) (Academia, 2004)

[29] G. Sonnert, Social Studies of Science 39, 927 (2009), pMID: 20506745

[30] L.J. Sax, K.L. Wartman, Studying the Impact of Parental Involvement on College Student Develop- 
ment: A Review and Agenda for Research (Springer Netherlands, Dordrecht, 2010), pp. 219-255, ISBN 978-90-481-8598-6

[31] A.S. Kazi, A. Akhlaq, Journal of research and reflections in education 11, 187 (2017)

[32] A. Soltani, A. Izquierdo, Nat Rev Neurosci 20, 635-644 (2019)

[33] J. White, Advancing Family Theories (SAGE Publications, Inc., 2005), http://sk.sagepub.com/ books/advancing-family-theories

[34] T.A. Podolskaya, A.V. Utenkov, Psychology in Russia: State of the Art 11, 84 (2018)
[35] O.V. Moskalenko, Problems of Psycho Didactics in University and Possible Ways of Their Solution, in SOCIETY. INTEGRATION. EDUCATION. Proceedings of the International Scientific Conference (Rezekne Academy of Technologies, 2017), Vol. 1, pp. 305-318, http://journals.rta.1v/index . php/SIE/article/view/2273

[36] T.M. Tytarenko, Zhyttievyi svit osobystosti: $u$ mezhakh i za mezhamy budennosti (The life world of the individual: within and outside of everyday life) (Lybid, 2003)

[37] J. Ratcliffe, Journal of Aesthetic Nursing 3, 358 (2014) 